\title{
The improvement in school aged children with asthma during the Covid-19 pandemic
}

\author{
Zülfikar Akelma ${ }^{1}$, Nevzat Başkaya ${ }^{2}$, Sema Cetin ${ }^{3}$, Ilknur Bostanci' ${ }^{4}$, and Serap Ozmen ${ }^{5}$ \\ ${ }^{1}$ Ankara Yildirim Beyazit University \\ ${ }^{2}$ University of Health Sciences, Dr. Sami Ulus, Maternity Child Health and Diseases \\ Training and Research Hospital, \\ ${ }^{3}$ SBU Ankara Dr Sami Ulus Maternity Child Health and Diseases Training and Research \\ Hospital \\ ${ }^{4}$ Dr. Sami Ulus Children's Research Hospital \\ ${ }^{5}$ Dr. Sami Ulus Woman's Health and Children Education and Research Hospital
}

January 27,2022

\begin{abstract}
Introduction: A number of measures were began due to coronavirus 2019 disease (Covid-19) pandemic in many countries worldwide. A lockdown was applied for aged $<18$ years, education was continued online, and wearing a mask became mandatory in public places, which created an unprecedented period for children. Real-life data is limited showing how children with asthma are affected due to major changes. This study reveal how asthmatic children are affected by pandemic conditions based on real-life data. Methods: Patients with asthma aged 6-18 years who were followed up in March, April, and May 2019-before the Covid-19 pandemic-were included in the study. Data from March-April-May 2020 and 2019 were compared to reveal the effects of the pandemic-related lifestyle changes on symptoms, frequency of exacerbations, and drug use in asthmatic children. Results: A total of 86 children with asthma aged 6-18 years were included in this study. Time spent inside the home was significantly higher in 2020 than in 2019. Need for rescue medications and emergency department visits were significantly lower in 2020 compared to 2019 ( $\mathrm{p}<0.001$ ). The number of well controlled patients with asthma was higher in 2020 than in 2019 (p $<0.0001$ ). Number of patients using prophylactic drugs within the last 3 months was lower in 2020 compared to 2019 ( $\mathrm{p}=$ 0.007). Conclusion: The present study provides valuable insights into the condition of children over the age of 6 years during the Covid-19 pandemic based on real-life data. During the pandemic period, the number of asthmatic exacerbations, rescue drug use and asthma control were positively affected in school aged children with asthma.
\end{abstract}

\section{Hosted file}

Manuscript.doc available at https://authorea.com/users/457415/articles/554202-theimprovement-in-school-aged-children-with-asthma-during-the-covid-19-pandemic

\section{Hosted file}

Tables.doc available at https://authorea.com/users/457415/articles/554202-the-improvementin-school-aged-children-with-asthma-during-the-covid-19-pandemic 